\title{
Engineering Design of a Device for Shearing Metal Sheets in a Non-conventional Way
}

Ján Moravec ${ }^{1}$, Miroslav Blatnický ${ }^{2}$, Ján Dižo ${ }^{2}$

${ }^{1}$ Department of Technological Engineering, Faculty of Mechanical Enginering, University of Žilina. Univerzitná 8215/1, 01026 Žilina. Slovak Republic. E-mail: jan.moravec@ffstroj.uniza.sk

${ }^{2}$ Department of Transport and Handling Machnines, Faculty of Mechanical Engineering, University of Žilina. Univerzitná 8215/1, 01026 Žilina. Slovak Republic. E-mail: miroslav.blatnicky@fstroj.uniza.sk, jan.dizo@fstroj.uniza.sk

This constribution presents the engineering design of the non-conventional shearing device, which uses for the operation the magnetic field. There is a prototype of the device designed and constructed in laboratory conditions. There are presented all relevant and necessary data of this shearing device supported by figures and scheme. The principle of the device operation consists in the fact that a sheet passes through feed rollers into the shearing position, i.e. into the position between two blades. Lower is fixed and the upper is guided in rails and controlled by means of springs. After the material dividing the electric circuit is interrupted and the moving blade returns into the starting position due to spring's action. This process of metal shearing can be quite simply automated. We have performed same experimental works using this device. There were sheared same sheet samples and the comparision of surfaces are shown. The use of our our device has proven to be appropriate for shearing sheets made of aluminium alloys with the thickness of $0.3 \mathrm{~mm}$.

Keywords: Shearing, Non-conventional method, Magnetic field, Differential equation

\section{Introduction}

Unconventional ways in forming processes prove to be the steady path in solutions of practical problems of manufacturing process. The question remains, how long we will be able to talk about a strict division of forming between conventional and unconventional. The line between both of them will surely disappear in time. At first glance, the less common methods show one fact, that unlike conventional methods, they are more dependent on physical findings. One of the possible ways of dividing of material by using the magnetic field (force) is described in the following text.

We have dedicated a few years on the Faculty of Mechanical Engineering in the University of Žilina for an application of a magnetic field in forming processes. This can be found in several contributions $[18,19]$. The shearing with the magnetic field is mentioned in works of number of authors, e.g. Bača [1], Dobrovolný [3], Hosford [7] and also Moravec [20, 21].

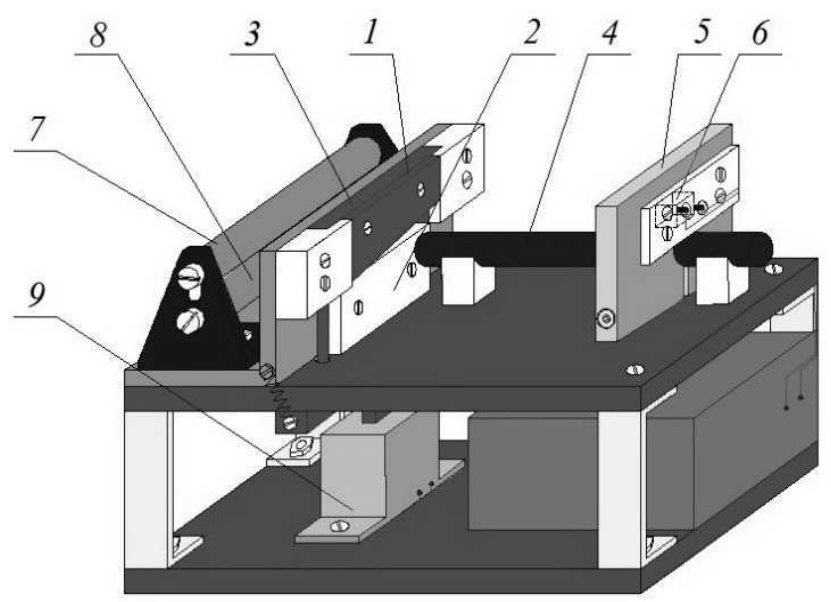

\section{Design of the shearing device}

This was the impulse for a development of the solution presented in this contribution. It is based on the common shearing procedure: a material (metal sheet) passes through feed cylinders into the shearing position and goes between two blades [8]. But, the device innovation consists in the fact, that the lower blade is fixed and the upper blade is guided in rails and handled by magnetic field and two springs. On the right side there is used such a stop component, which based on the metal sheet detection engages an electric circuit and the upper blade is moved into the shearing action. After the material is separated, the electrical circuit is interrupted and the blade returns to a starting position due to generated forces in springs. A new required dimension is set only by stop komponent aktivity. In this contribution the construction solution of this tool is described including the operation principle $[7,16,17]$. Sheet metal shearing device with application of electromagnet is shown in Fig. 1.

$$
\begin{aligned}
& \text { Legend: } \\
& 1 \text { - upper moving blade } \\
& 2 \text {-lower fixed blade } \\
& 3 \text { - blade guidance } \\
& 4 \text { - cylindrical guidance of a sheet metal } \\
& 5 \text { - stop component } \\
& 6 \text { - end switch } \\
& 7 \text { - upper adjustable guidance cylinder } \\
& 8 \text { - lower guidance cylinder } \\
& 9 \text { - electromagnet }
\end{aligned}
$$

Fig. 1 Sheet metal shearing device with the application of an electromagnet 
The alternating voltage of $230 \mathrm{~V}$ is fed to input terminals of the TR transformer. The transformer transforms alternating voltage from $230 \mathrm{~V}$ to the alternating voltage of $24 \mathrm{~V}$ (Fig. 2), which is fed to the input of the rectifier. Alternating voltage of $24 \mathrm{~V}$ is transformed to the direct voltage with transition through Gretz bridge composed of D1 - D4 diodes (Fig. 2). The partially rectified voltage behind the output of Gretz bridge is passed to the filtrating part made of $\mathrm{C} 5$ and $\mathrm{C} 8$ capacitors, which filtrate the voltage and create the rectified voltage of $24 \mathrm{~V}$. The rectified voltage is stabilized by the MA 7805 stabilizer. The rectified stabilized voltage of $24 \mathrm{~V}$ gets to the output of the rectifier. This voltage is connected to the input of the electromagnet after the button is pressed by a sheared metal sheet $[9,10,14,24]$.

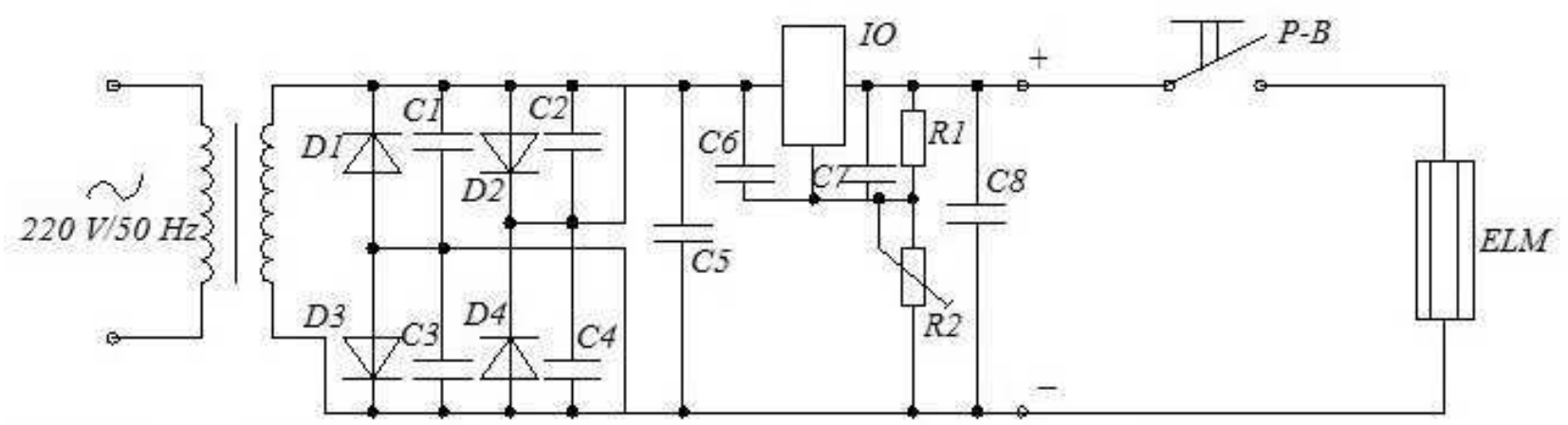

Legend: $\quad$ D1, D2, D3, D4 - diode $K 4$ 130/80-4pcs

$\mathrm{Cl}, \mathrm{C} 2, \mathrm{C3}, \mathrm{C4}, \mathrm{C6}, \mathrm{C} 7$-capacitors $100 \mathrm{nF}, \mathrm{Tk}$ 784-6pcs

$R 2$ - potentiometer

C5, C8-capacitors $470 \mu F / 40 \mathrm{~V}$, TF 010-1pc

ELM-electromagnet

R1-resistor $100 \Omega, T R 223-1 p C$

IO-stabilizer MA 7805-1pc

P-B - push-button

Fig. 2 Adjustable voltage source diagram

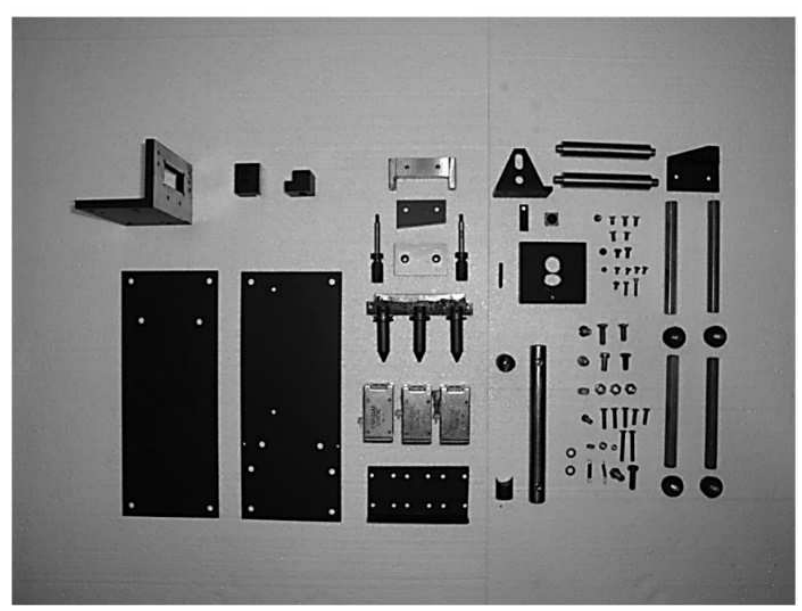

Fig. 3 Individual components of the shearing device

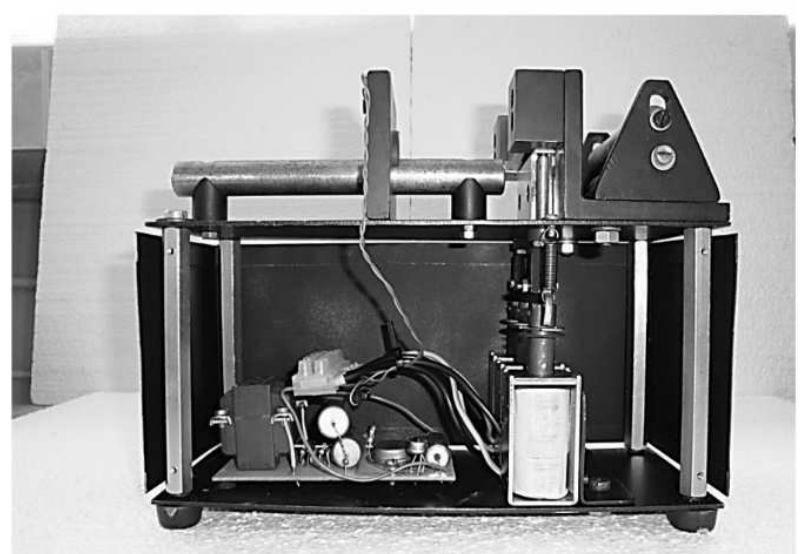

Fig. 4 Assembled shearing device
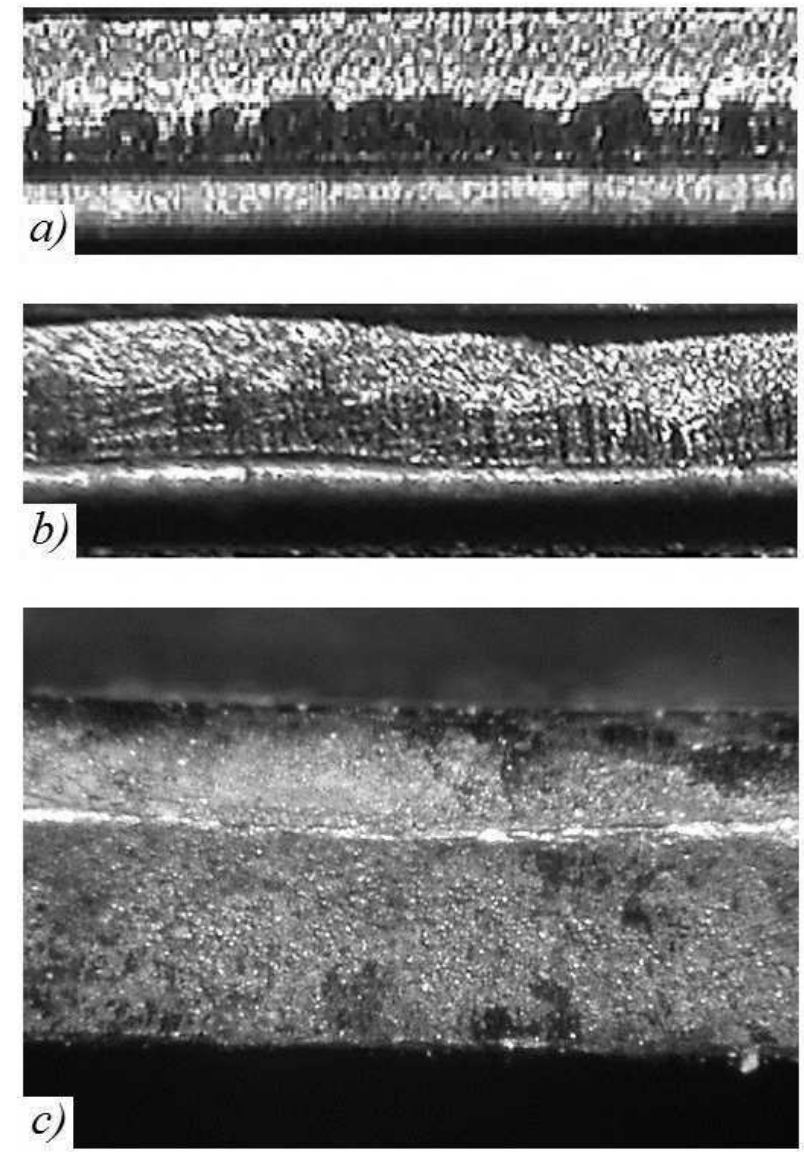

Fig. 5 Comparision of sheared surfaces appearance (magnified 20 times): a) newly designed shearing device, b) shearing on lever shears, c) shearing on a conventional device 


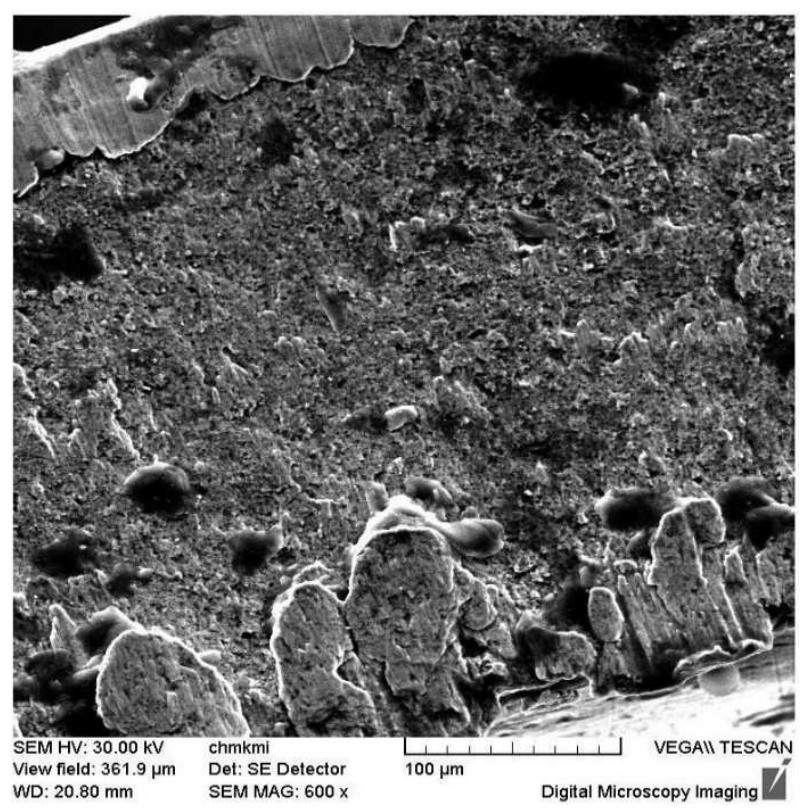

Fig. 6 Microstructure of aluminium surface sheared on the new designed shearing device

Figure 3 shows individual components of the unconventional device for the metal sheet shearing using the electromagnetic field and Figure 4 shows the assembled shearing device.

We have already performed same laboratory tests using this new designed sparing device. From results it proved, that the device operates and works correctly. According to tests, the device is able to shear metal sheets made of aluminium alloys $[11,12]$. In laboratory conditions there were tested various thicknesses of sheets up to

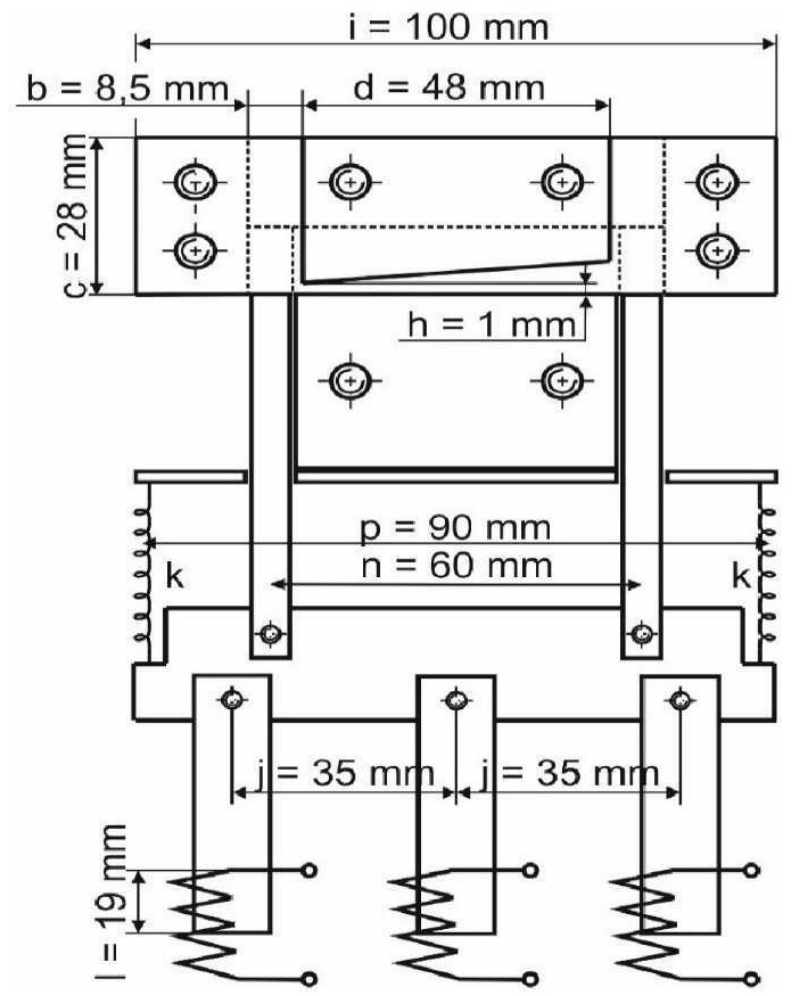

$0.6 \mathrm{~mm}$, but the device is most effective for the thickness up to $0.3 \mathrm{~mm}$. Moreover, we found out, that the shearing process realised by means of this device can be relatively simple automated.

In testing forming devices and tools it is customary to compare the quality of samples surfaces [25]. The comparision of sheared surfaces of aluminium alloy laboratory samples from non-convetional and convantional shearing devices and microstructure are shown in Fig. 3 and Fig. 4.

In Fig. 3 we can see, that the quality of the sheared surface from the new designed non-convetional seharing device (Fig. 3 a) is comparable with convetional ways of shearing (Fig. 3 b and Fig. 3 c). Further, the microstruture of the sheared sample surface from the non-conventional shearing device (Fig. 4) is very similar to sheared surfaces of the same material from conventional shearing devices $[2,13,26]$. Therefore, from this point of view we can conclude, that our device can find application there, where we would be able to utilize the automated proces of shearing while maintaining sufficient guality of a sheet shear.

\section{Analysis of the device mechanism and the equation of motion}

In this section, the mathematical description of the device is introduced. Based on it we are able to perform analyses of dynamic properties [4, 5, 15] and from that it is possible to determine all parameters needed for proper and effective operation of the device and also alternatively it could serve as a base of a multibody model $[6,22$, $23,27]$.

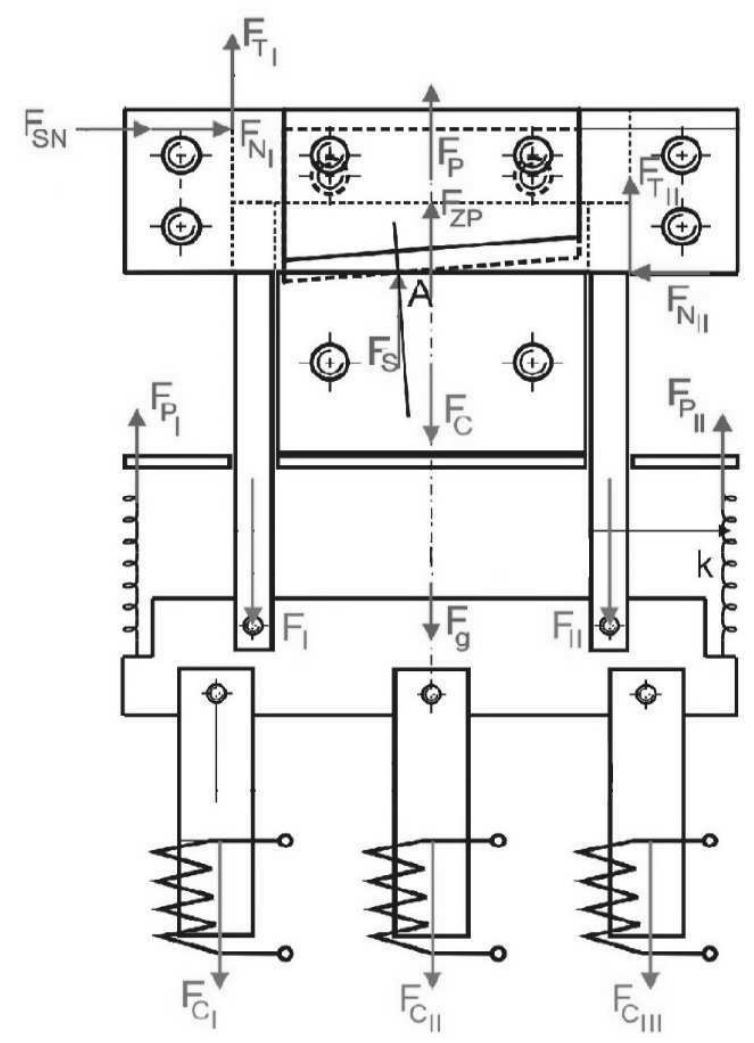

Fig. 7 Two-dimensional model of the moving part of the mechanism (left) and marking forces and reactions (right) 
The mechanism moves in the vertical direction (" $x$ " direction) by means of three coils. When the electric current is switched on, in coils generate a force, which is needed for the sheet shearing and for the overcoming of the passive resistanes, springs stiffnesses, the guidances jamming and the inertia mass of moving masses. The task is to derivate all variable force effects by means of a variable, called " $x$ ", which represents the displacement of the shear blade with the deffined cant of 9.5 , which is expressed by two variables $r$ and $t$, i.e. $r: t=1: 9.5$. To this value the inclination angle of the inclined plane corresponds and it is given:

$$
\tan \alpha=\frac{t}{r}
$$

Solving the equation (1) we get the angle value

$$
\tan \alpha=\frac{t}{r}=\frac{1}{9.5}=0.10526 \Rightarrow \alpha=6^{\circ} .
$$

The necessary partial step for the mathematical description of the meshanism is the determination the inclination angle value is, because the shearing point location (i.e. the contact point of the shearing blade and a sheet) will be determined by the , $x$ “ coordinate expressly, therefore the line function is given by the tangent of the inclination angle. It follows from knowledge of the planimetry.

Let's image the solving task in the suitable view and mark the mechanism geometry (Fig. 5 left). There are shown are parameters, which influane a calculation and geometric coefficients of a structure and which are needed for an analytical calculation. For the possibility of the shearing a sheet with the maximum width $d$ of $48 \mathrm{~mm}$ (i.e. width of the shearing blade) and with the maximum depth up to $1 \mathrm{~mm}$ the clearence $h$ of $1 \mathrm{~mm}$. The mass of the laterally reversibly moving part of the construction was determined by the measurement to be $m_{p}=0.344 \mathrm{~kg}$ at the gravitational acceleration of $g=9.81 \mathrm{~m} \cdot \mathrm{s}^{-2}$. For the reverse motion ensuring we have used two pulling springs with the stiffness $k$ of $0.79 \mathrm{~N} \cdot \mathrm{mm}^{-1}$ and with the preload $F_{0}$ of $1.78 \mathrm{~N}$ in the unloaded state. It is the reversing force and it equals to the gravitational which equals to the gravitational force of the moving part of the construction, thus

$$
2 \cdot F_{0} \geq m_{p} \cdot g .
$$

The solution of the equation (3) results to

$$
\begin{aligned}
& 2 \cdot 1.78 \geq 0.344 \cdot 9.81 \\
& 3.56 N \geq 3.375 N
\end{aligned}
$$

Analysing the force effects of this device we have found out, that the preload force of the unloaded force F0, the gravitational force of the moving masses Fg and the required shearing force $F s$ are constant forces. It means, that values of these forces do not depend neihter on time nor on the parameter , $x$ “, i.e. it does not depend on a shift of the shearing blade form the zero (boundary) value $(x=0 \mathrm{~mm})$. All others forces are, however, a function of the shearing blade shifting and, therefore i tis necessary to express them in such a form and write them into the resulting equation of motion. For its determination the static method was used. Figure 5 right shows all force effects generated during the device operation at the general shifting,,$x^{6}$.

The axial spring forces $F_{P I}$ and $F_{P I I}$ is increasing from the original preload force $F_{0}$ due to its stiffness and deformation to the value given by follong equation

$$
F_{P I}=F_{P I I}=F_{0}+k \cdot x \text {. }
$$

The forces of electric coils (coils are three) could be defined by the formula

$$
F_{C I}=F_{C I}=F_{C I I I}=B \cdot I \cdot(l+x),
$$

where $B\left[\mathrm{~kg} \cdot \mathrm{A}^{-1} \cdot \mathrm{s}^{-2}\right]$ is the magnetic induction of coils, $I[\mathrm{~A}]$ is the electric current in a conductor and $l[\mathrm{~m}]$ is the effective length of a conductor passing through coils which is changing form the original value $l$ due to the shearing blade shifting by the " $x$ " value to the new length $l+x$ (Fig. 5 right). Because of the uneven run, varying position of the shear force $F_{s}$ and the inclination of the shearing contact point with the sheet metal at the $\alpha$ angle, the normal forces $F_{N I}, F_{N I I}$ and $F_{S N}$ occur in the guidance. The nature of the mechanism gives, that normal forces $F_{N I}$ and $F_{S N}$ will change the perpendicular distance of their vector line (they act on the common line) depending on the " $x$ " distance, i.e. there is a change of in the magnitude of the moment inductive of the guidance jamming and also a change of resistances. In constrast to this, the $F_{N I I}$ force will not change its point of action, because the contact between the guidance and shifting body remains in the same place. Normal components of $F_{N I}, F_{N I I}$ and $F_{S N}$ forces will cause the generation of $F_{T I}$ and $F_{T I I}$ friction forces because of the friction coefficient $(f=0.1$ [-], i.e. dry friction steel - steel).

We have used the symetry of the moving body and also considered the fact, that there are used coils with the same parameters. The task can by simplify, if we assume, the force effect is equivalent with the $F_{C I}, F_{C I I}$ and $F_{C I I}$ forces of coils and it is applied into the guidances ens and, that $\mathrm{i}$ tis represented by the $\mathrm{F}_{\mathrm{I}}$ and $\mathrm{F}_{\mathrm{II}}$ forces at which

$$
F_{C I}+F_{C I I}+F_{C I I}=F_{I}+F_{I I} .
$$

Subsequently FI and FII forces are put together into the $F_{C}$ resultant force, which is applied to the vector line (vertical symetry axis ot the mechanism) shared with the $F_{g}$ gravitational force, the $F_{Z P}$ force of inertial masses as well as with the $F_{P}$ resultant force of sprint because we can apply the symetry of the mechanism. For generated forces $\left(F_{T I}, F_{T I I}\right)$ the Coulomb law is valid and resulting to

$$
\begin{aligned}
& F_{T I}=\left(F_{N I}+F_{S N}\right) \cdot f \\
& F_{T I I}=F_{N I I} \cdot f
\end{aligned}
$$

For the equilibrium of force effects generated during the mecahnism operation we can write (in accordance with Fig. 5) following

$$
\sum F_{i y}=0 \Rightarrow F_{S N}+F_{N I}-F_{N I}=0 .
$$

Adjusting equation (9) results to

$$
F_{N I I}=F_{S N}+F_{N I},
$$

$\sum F_{i x}=0 \Rightarrow F_{P I}+F_{P I I}-F_{g}-F_{C}+F_{S}+F_{T I}+F_{T I I}=0$, 


$$
\begin{aligned}
& \sum M_{i A}=0 \Rightarrow-F_{S N} \cdot(c-x)-F_{N I} \cdot(c-x)-F_{T I} \cdot\left(b-l_{1}\right)+ \\
& +F_{N I I} \cdot 0+F_{T I I} \cdot\left(d+b-l_{1}\right)+F_{P I} \cdot\left(\frac{d}{2}-l_{1}\right)+F_{P I I} \cdot\left(\frac{d}{2}-l_{1}\right)- \\
& -F_{g} \cdot\left(\frac{d}{2}-l_{1}\right)-F_{C} \cdot\left(\frac{d}{2}-l_{1}\right)=0
\end{aligned}
$$

In equation (12) the $l_{l}$ lenght represents a variable value, which directly depends on the shearing blade displacement,$x^{“}$. For this reason, $\mathrm{i}$ tis necessary to find the function of the line, which describes the $l_{l}$ lenght change depend on the , $x$ “ displacement of the shearing blade. From the planimetry and Fig. 5 we get the relation

$$
\begin{aligned}
& -F_{S N} \cdot(c-x)-F_{N I} \cdot(c-x)-F_{T I} \cdot\left(b+\frac{x-h}{\tan \alpha}\right)+F_{N I} \cdot 0+ \\
& +F_{T I I} \cdot\left(d+b-\frac{x-h}{\tan \alpha_{1}}\right)+F_{P I} \cdot\left(\frac{d}{2}-\frac{x-h}{\tan \alpha}\right)+F_{P I I} \cdot\left(\frac{d}{2}-\frac{x-h}{\tan \alpha}\right)- \\
& -F_{g} \cdot\left(\frac{d}{2}-\frac{x-h}{\tan \alpha}\right)-F_{C} \cdot\left(\frac{d}{2}-\frac{x-h}{\tan \alpha}\right)=0
\end{aligned}
$$

In eq. (14), the $F_{N I}$ force represents an unknown quantity, which we just express

$$
\begin{aligned}
& -F_{N I} \cdot\left(c-x+f \cdot b+f \cdot \frac{x-h}{\tan \alpha}-f \cdot d-f \cdot b+f \cdot \frac{x-h}{\tan \alpha}\right)- \\
& -F_{S} \cdot\left(-x \cdot \tan \alpha+f \cdot b \cdot \tan \alpha-f \cdot \frac{x-h}{\tan \alpha} \cdot \tan \alpha+c \cdot \tan \alpha-f \cdot d \cdot \tan \alpha-\right. \\
& \left.-f \cdot b \cdot \tan \alpha+f \cdot \frac{x-h}{\tan \alpha} \cdot \tan \alpha\right)+F_{P I} \cdot\left(\frac{d}{2}-\frac{x-h}{\tan \alpha}\right)+F_{P I I} \cdot\left(\frac{d}{2}-\frac{x-h}{\tan \alpha}\right)- \\
& -F_{g} \cdot\left(\frac{d}{2}-\frac{x-h}{\tan \alpha}\right)-F_{C} \cdot\left(\frac{d}{2}-\frac{x-h}{\tan \alpha}\right)=0, \\
& F_{N I}=\frac{\left(F_{P I}+F_{P I I}-F_{g}-F_{C}\right) \cdot\left(\frac{d}{2}-\frac{x-h}{\tan \alpha}\right)-F_{S} \cdot \tan \alpha \cdot(c-x-f \cdot d)}{c-x+2 \cdot f \cdot \frac{x-h}{\tan \alpha}-f \cdot d} .
\end{aligned}
$$

Then, the $F_{N I I}$ force is given by following

$$
F_{N I I}=\frac{\left(F_{P I}+F_{P I I}-F_{g}-F_{C}\right) \cdot\left(\frac{d}{2}-\frac{x-h}{\tan \alpha}\right)-F_{S} \cdot \tan \alpha \cdot(c-x-f \cdot d)}{c-x+2 \cdot f \cdot \frac{x-h}{\tan \alpha}-f \cdot d}+F_{S} \cdot \tan \alpha
$$

and considering eqs. (8) the $F_{T I}$ and $F_{T I I}$ friction forces we can express as

$$
\begin{gathered}
F_{T I}=\left(\frac{\left(F_{P I}+F_{P I I}-F_{g}-F_{C}\right) \cdot\left(\frac{d}{2}-\frac{x-h}{\tan \alpha}\right)-F_{S} \cdot \tan \alpha \cdot(c-x-f \cdot d)}{c-x+2 \cdot f \cdot \frac{x-h}{\tan \alpha}-f \cdot d}\right) \cdot f, \\
F_{T I I}=\left(\frac{\left(F_{P I}+F_{P I I}-F_{g}-F_{C}\right) \cdot\left(\frac{d}{2}-\frac{x-h}{\tan \alpha}\right)-F_{S} \cdot \tan \alpha \cdot(c-x-f \cdot d)}{c-x+2 \cdot f \cdot \frac{x-h}{\tan \alpha}-f \cdot d}+F_{S} \cdot \tan \alpha\right) \cdot f .
\end{gathered}
$$

Considering the inertia effects of the shearing blade, we can write, that

$$
\sum F_{i x}=0 \Rightarrow F_{Z P}+F_{P I}-F_{P I I}+F_{S}+F_{T I}+F_{T I I}-F_{g}-F_{C}=0 .
$$

When we subtitute formulas describing the corresponding forces by means of the , $x^{\prime \prime}$ variable into the eq. (20),

we get following equation 


$$
\begin{aligned}
& m_{P} \cdot \frac{d^{2} x}{d t^{2}}+\left(F_{0}+k \cdot x\right)+\left(F_{0}+k \cdot x\right)+F_{S}+ \\
& +\left(\frac{\left(F_{P I}+F_{P I I}-F_{g}-F_{C}\right) \cdot\left(\frac{d}{2}-\frac{x-h}{\tan \alpha}\right)-F_{S} \cdot \tan \alpha \cdot(c-x-f \cdot d)}{c-x+2 \cdot f \cdot \frac{x-h}{\tan \alpha}-f \cdot d}+F_{S} \cdot \tan \alpha\right) \cdot f+ \\
& +\left(\frac{\left(F_{P I}+F_{P I I}-F_{g}-F_{C}\right) \cdot\left(\frac{d}{2}-\frac{x-h}{\tan \alpha}\right)-F_{S} \cdot \tan \alpha \cdot(c-x-f \cdot d)}{c-x+2 \cdot f \cdot \frac{x-h}{\tan \alpha}-f \cdot d}+F_{S} \cdot \tan \alpha\right) \cdot f-F_{g}- \\
& -3 \cdot B \cdot I \cdot(l+x)=0 .
\end{aligned}
$$

Now, let's use the simplification in the form of the equivalence $2 \cdot F_{0}=F_{g}$ and separate the , $x$ " variable in the

$$
\begin{aligned}
& m_{P} \cdot \frac{d^{2} x}{d t^{2}}=3 \cdot B \cdot I \cdot(l+x)-2 \cdot k \cdot x-F_{S}- \\
& -2 \cdot f \cdot\left(\frac{2 \cdot\left(F_{0}+k \cdot x\right)-F_{g}-3 \cdot B \cdot I \cdot(l+x) \cdot\left(\frac{d}{2}-\frac{x-h}{\tan \alpha}\right)-F_{S} \cdot \tan \alpha \cdot(c-x-f \cdot d)}{c-x+2 \cdot f \cdot \frac{x-h}{\tan \alpha}-f \cdot d}+F_{S} \cdot \tan \alpha\right) .
\end{aligned}
$$

Equation (22) represents the equation of motion, which describes the motion of the shearing blade during operation in any position of its, i.e. for any value of the ,$x^{6}$ variable.

\section{Conclusion}

The engineering design of the introduced shearing device, which uses electromacnetic forces was presented in this contribution. Based on the experimental operation in laboratory it proves, that using this device is quite effective for the shearing metal sheets made of aluminium alloys up to thickness of $0.6 \mathrm{~mm}$. The force, which is needed for the material sheating, directly depends on the force of the chosen electromagnet. Such a shearing way turns out to be effective, suitable and reasonable alternative to standard shearing methods even to be easier automated than standard methods.

\section{References}

[1] BAČA, J., BÍLIK, J., TITTEL, V. (2010). Technology of metal forming (In Slovak). Pp. 245, Slovak University of Technology, Bratislava, ISBN 97880-227-3242-0.

[2] BOLIBRUCHOVÁ, D., BRŮNA, M. (2017). Impact of the elements affecting the negative ironbased phases morphology in aluminium alloys summary results. Manufacturing Technology, Vol. 17, No. 5, pp. 675-679, ISSN 1213-2489.

[3] DOBROVOLNÝ, B. (1946). Design of tools for presses (In Slovak). Pp. 784, Josef Hork publisher, Prague.

[4] GERLICI, J., LACK, T., HARUŠINEC, J. (2014). Development of test stand prototype for differential form in eq. (19). We get equation in following form rail vehicles brake componets testing. Communications - Scientific Letters of the University of Zilina, Vol. 13, No. 3a, pp. 27-32, ISSN 13354205.

[5] GERLICI, J., LACK, T., HARUŠINEC, J. (2013). The test stand load modulus implementation for the realistic railway operation in the laboratory conditions. Manufacturing Technology, Vol. 13, No. 4, Pp. 444-449, ISSN 1213-2489.

[6] HAUSER, V., NOZHENKO, O., KRAVCHENKO, K., LOULOVÁ, M., GERLICI, J., LACK, T. (2017) Proposal of a mechanism for seting bogie wheelsets to radial position while riding along track curve. Manufacturing Technology, Vol. 17, No. 2, Pp. 186-192, ISSN 1213-2489.

[7] HOSFORD, W. F., CADDEL, R. M. (2011). Metal forming, mechanics and metallurgy. Cambridge University Press, ISBN 978-1-10700452-8.

[8] HRONEK, O., ZETEK, M., BAKŠA, T., ADÁMEK, P. (2017). Quality of the cutting tool microgeometry for machining aluminium alloys. Manufacturing Technology, Vol. 17, No. 4, pp. 463-469, ISSN 1213-2489.

[9] JOHNSON, W., MAMALIS, A. G. (1978). Plasticity and metal forming. Hellenic Steel Publication, Thessaloniki, Greece, pp. 85.

[10] JOHNSON, W., MELLOR, P. B. (1962). Plasticity of mechanical engineers. London: D. von Nostrad Co. Ltd.

[11] JÓZWIK, J., MIKA, D., DZIEDZIC, K. (2016). Vibration of Thin Walls during Cutting Process of 
7075 T651 Aluminium Alloy, Manufacturing Technology, Vol. 16, No. 1, pp. 113-120, ISSN 1213-2489.

[12] KLIMENDA, F., SOUKUP, J., ŽMINDÁK, M. (2016). Deformation of aluminium thin plate. $M a$ nufacturing Technology, Vol. 16, No. 1, pp. 124129, ISSN 1213-2489.

[13] KUCHARIKOVÁ, L., TILLOVÁ, E., UHRÍČIK, M., BELAN, J., ŠVECOVÁ, I. (2017). Highcycles fatique of different casted secondary aluminium alloy. Manufacturing Technology, Vol. 17, No. 5, pp. 756-761, ISSN 1213-2489.

[14] KUMAR, S. (2008). Technology of metal forming processes. PHI Learning Private Limited, New Delhi, India, ISBN 879-81-203-3425-0.

[15] LACK, T., GERLICI, J. (2013) The FASTSIM method modification to speed up the calculation of tangential contact stresses between wheel and rail. Manufacturing Technology, Vol. 13, No. 4, pp. 486-492, ISSN 1213-2489.

[16] Metal Forming Handbook. (1988). Springer-Verlag Berlin Heidelberg, ISBN 3-540-61185-1.

[17] MIELNIK, M. E. (1991). Mechanical metallurgy. McGraw, Hill Book Company, New Your.

[18] MORAVEC, J. (2005). Magnetism in forming (In Slovak). EDIS - University of Žilina publisher, 133 pages, ISBN 978-80-8070-385-X.

[19] MORAVEC, J. (2011). Non-conventional forming methods (In Slovak). EDIS - University of Žilina publisher, 187 pages, ISBN 978-80-5540389-2.

[20] MORAVEC, J. et al. (2011). Shaping tools (In Slovak). EDIS - University of Žilina publisher, 330 pages, $2^{\text {nd }}$ edition, ISBN 978-80-554-0446-2.
[21] MORAVEC, J., STROKA, R. (2009). Application of an electromagnetism in integrated blanket technologies (In Slovak). EDIS - University of Žilina publisher, 138 pages, ISBN 978-80-554000-8.

[22] SAPIETOVÁ, A., DEKÝY̌s, V. (2016). Use of MSC.ADAMS software product in modelling vibration sources. Communications - Scientific Letters of the University of Zilina, Vol. 18, No. 1a, pp. 101-107, ISSN 1335-4205.

[23] SAPIETOVÁ, A., SÁGA, M., HYBEN, B., SAPIETA, M. (2014). Effective methods of parameters refinement of machinery in the program MSC. ADAMS. Applied Mechanics and Material, Vol. 611, pp. 67-74, ISSN 1660-9336.

[24] STOROŽEV, M. V., POPOV, J. A. 1978. Theory of metal forming (In Slovak). Pp. 486, ALFA Publisher, Bratislava.

[25] ŠPALEK, F., SADÍLEK, M., ČEP, R., PETRŮ, J., KRATOCHVÍL, J., ČEGAN, T. (2017). Difference between cutting surface of $\mathrm{Al}$ foam and solid Al machined by WEDM technology. Manufacturing Technology, Vol. 17, No. 5, pp. 853858, ISSN 1213-2489.

[26] UHRÍČIK, M., PALČEK, P., CHALUPOVÁ, M., ORŠULOVÁ, T. (2017). The structure of the aluminium alloy and its influence on the fatique properties. Manufacturing Technology, Vol. 17, No. 5, pp. 863-869, ISSN 1213-2489.

[27] VAVRO, J. jr., VAVRO, J., KOVÁČIKOVÁ, P., BEZDEDOVÁ, R., HÍREŠ, J. (2017). Kinematic and dynamic analysis and distribution of stress in items of planar mechanisms by means of the MSC ADAMS software. Manufacturing technology, Vol. 17, No. 2, pp. 267-370, ISSN 12132489. 